\title{
Digitalization: problems of its development in modern agricultural production
}

\author{
Viktor Alt ${ }^{1,2, *}$, Svetlana Isakova $^{1}$, and Elena Balushkina ${ }^{1}$ \\ ${ }^{1}$ Siberian Federal Scientific Centre of Agro-BioTechnologies of the Russian Academy of Sciences, \\ 630501, Krasnoobsk, PO Box 463, Novosibirsk region, Russian Federation \\ ${ }^{2}$ Novosibirsk state technical University, 660073, avenue Karl Marx, 20, Novosibirsk, Russian \\ Federation
}

\begin{abstract}
The analysis shows that the degree of implementation of digital technologies differs in different countries, with Russia significantly lagging behind the leading countries. The purpose of the research is to analyze the current state of digitalization of agriculture, identify problems of its development in the process of digital transformation of the agricultural economy and ways to solve them. The factors that hinder the digitalization of agriculture are highlighted. These are limiting grain production and difficult to predict, psychological barriers and insufficient training (including IT specialists), the availability of investment, the multidimensional component of production, and the availability of digital infrastructure. The solutions of selected problems are proposed : installation of local weather stations; training of IT specialists in the agriculture and learning agricultural workers the skills to work with modern technology; creating a single portal for farmers, with the possibility of exchanging information; improving the information infrastructure; creating strategies to implementing digital technologies.
\end{abstract}

\section{Introduction}

Trends in the development of modern society are associated with population growth. The world's population was 7.8 billion people in June 2020. It will grow 1.25 times by 2050 according to UN forecasts. It means that it will reach 9.1 billion people. The need for production also increases along with the increase in population, so one of the tasks of agriculture is to provide the population with food. It is necessary to increase the production of world agricultural food by $70 \%$ by 2050 . At the same time, the use of traditional methods and technologies of tillage in agriculture is no longer effective [1]. This means that production processes in agriculture should become as efficient as possible.

The use of intelligent technologies for the agricultural sector makes it possible to significantly increase its productivity, reduce production costs, and in many cases reduce labor requirements [2-3]. Thus, there is an inevitability of digitalization of all agricultural systems. This is achieved through the introduction of innovative (emergent) technologies such as artificial intelligence, robotics, IoT, unmanned aerial vehicles, as well as a number

\footnotetext{
* Corresponding author: altviktor@ngs.ru
} 
of new hardware, software, mobile applications, sensor technologies and big data processing systems [4-6].

Digitalization has an important role in agriculture in addressing challenges related to smart agriculture, sensors and traceability; smart logistics focused on real-time virtualization, connectivity and logistics intelligence; and smart food awareness focused on data transparency and knowledge representation [7-8]; improving food safety related to monitoring the application of crop protection and fertilizers [9-10].

Research on the impact of digitalization and the degree of its implementation in various sectors of agriculture is carried out all over the world, also it is studying the problems and weaknesses of the process of digitalization of the agricultural sector [11-13]. The analysis shows that the degree of implementation of digital technologies differs in different countries, with Russia significantly lagging behind the leading countries [14]. This confirms the relevance of research on the causes that hinder this process in agriculture in the Russian Federation and the search for ways to eliminate them based on the experience of other countries.

The purpose of the research is to analyze the current state of digitalization of agriculture, identify problems of its development in the process of digital transformation of the agricultural economy and ways to solve them.

\section{Materials and Methods}

The factors that prevent or hinder the introduction of digital technologies in various areas of the agro-industrial complex is the object of research. The assessment of the current state of agriculture digitalization in the Russian Federation was carried out. It was done in comparison with level of IOT implementation in the USA, Germany and Great Britain.

The factors that hinder the digitalization of agriculture are highlighted. These are limiting grain production and difficult to predict, psychological barriers and insufficient training (including IT specialists), the availability of investment, the multidimensional component of production, and the availability of digital infrastructure.

Analysis and generalization of available factors were carried out using information and analytical methods using system and logical analysis of materials.

\section{Results}

Agriculture is characterized by certain features: the multiplicity of factors characterized production and technological processes, the agro-climatic distribution of farms, the diversity of societies, also the multiplicity of species, breeds, varieties of animals and plants. The inevitability of incomplete information when making management decisions exists in agricultural production. This is due to the multifunctional nature of management facilities in agriculture. These include: the environment, land, plants, animals, machines and society (rural people with their environment: agro-climatic conditions, social conditions, financial and monetary structure of income and expenses, transport infrastructure, production logistics, etc.) (Fig.1). 


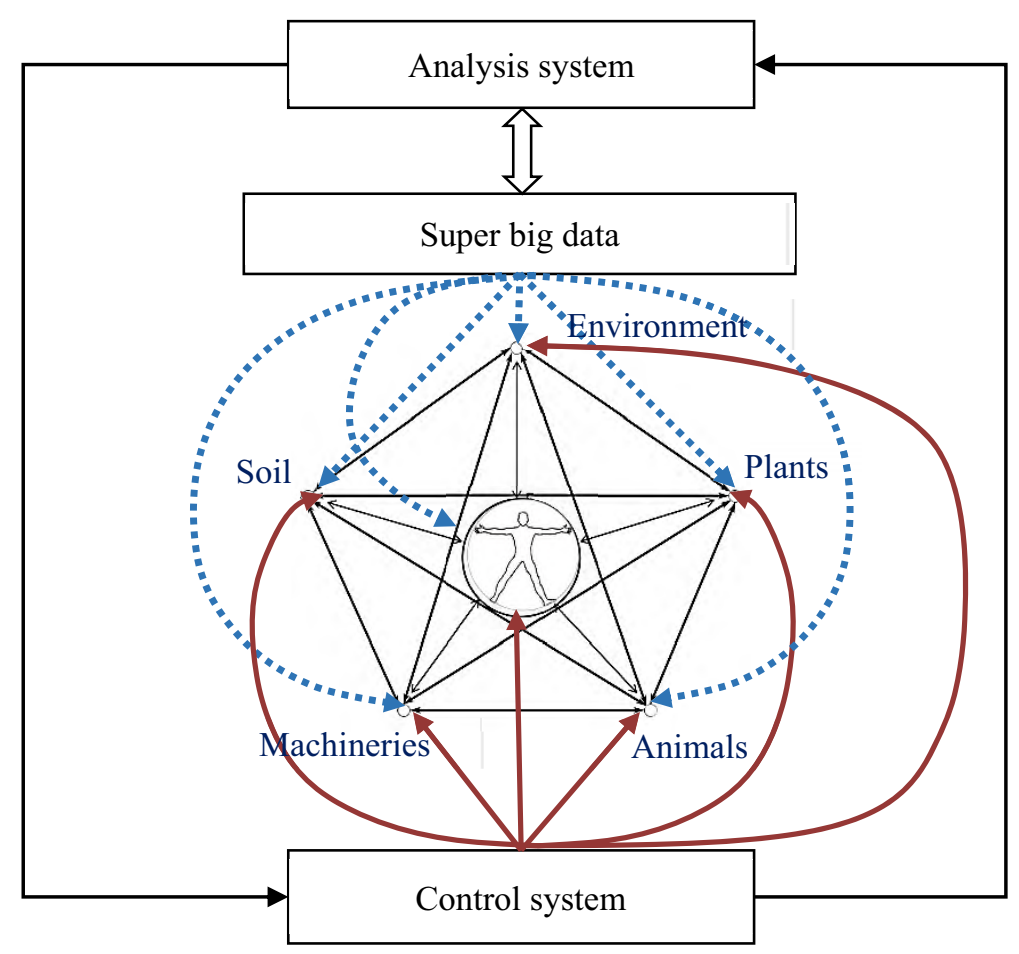

Fig. 1. Schematic representation of the relations of objects in agricultural production, reflecting their dialectical community.

These objects can be represented as eight (and in some cases twelve) types of resources that interact in a common set. Their multiplicative relationship is visible when considering these resources:

$$
F(t)=f_{1}(t) \times f_{2}(t) \times f_{3}(t) \times f_{4}(t) \times f_{5}(t) \times f_{6}(t) \times f_{7}(t) \times f_{8}(t),
$$

where: $F(t)$ - gross production of grain;

$f_{l}(t)$ - the functionality of the «plants resource»;

$f_{2}(t)$ - the functionality of the «machineries resource»;

$f_{3}(t)$ - the functionality of the «land resource»;

$f_{4}(t)$ - the functionality of the «environment resource»;

$f_{5}(t)$ - the functionality of the «animals resource»;

$f_{6}(t)$ - the functionality of the «socium resource»;

$f_{7}(t)$ - the functionality of the «financial resource»;

$f_{8}(t)$ - the functionality of the «infrastructural resource».

Expression (1) allows to describe the production process and also to anticipate the situation of development of the entire process as a whole and in its limitations [51]. Thus, this problem is represented as an eight-dimensional space. At the same time, it is difficult to imagine an automatic process of grain production (without human participation) even in a fundamental mathematical solution with complexity of descriptions of possible restrictions. A person, as a subject making managerial decisions, feels a four-dimensional space (width, length, height, and time). He, being in eight-dimensional space, feels a certain discomfort. Analysis of processes in eight-dimensional space is a task for a person of insurmountable complexity. Objectively, he is forced to make private decisions because of the complexity 
of accounting for all factors, and when making managerial decisions, mistakes are inevitable. Than digital technologies come to the aid of the manager.

The areas and directions in agriculture affected by digitalization are presented below:

- detection of diseases, pests and weeds by processing images obtained by drones using artificial intelligence;

- forecast weather conditions by receiving, processing and analyzing data from local weather stations and statistical data for previous periods;

- precision farming using GPS navigation, drones, digital mapping and soil assessment[16];

- application of fertilizers and protective equipment using the analysis of data obtained by aerial photography, crop monitoring and spot application of funds using GPS navigation [1];

- monitoring plant growth using drone flyovers, calculating vegetation indices, tracking product quality and forecasting yields;

- control of the production process using information systems that provide tools for economic and other calculations, field history and document management;

- monitoring of agricultural machinery using systems for tracking its movement, fuel consumption and remote monitoring of the state of equipment;

- purchase and sale of equipment using Internet portals, mobile applications, etc.

The program «Digital agriculture» was adopted to accelerate the pace of digitalization in Russian agriculture. It is similar to the foreign program «Agriculture 4.0». However, the use of digitalization products is at different levels in different countries. From 5 to $10 \%$ of arable land is processed using information technology in Russia. The level of information technology penetration exceeds $30 \%$ (in Canada up to $80 \%$ ) in the countries most developed in terms of agricultural equipment (USA, Germany, Canada) [17].

This difference in the level of application of digitalization products in Russia is associated with certain problems (figure 2).

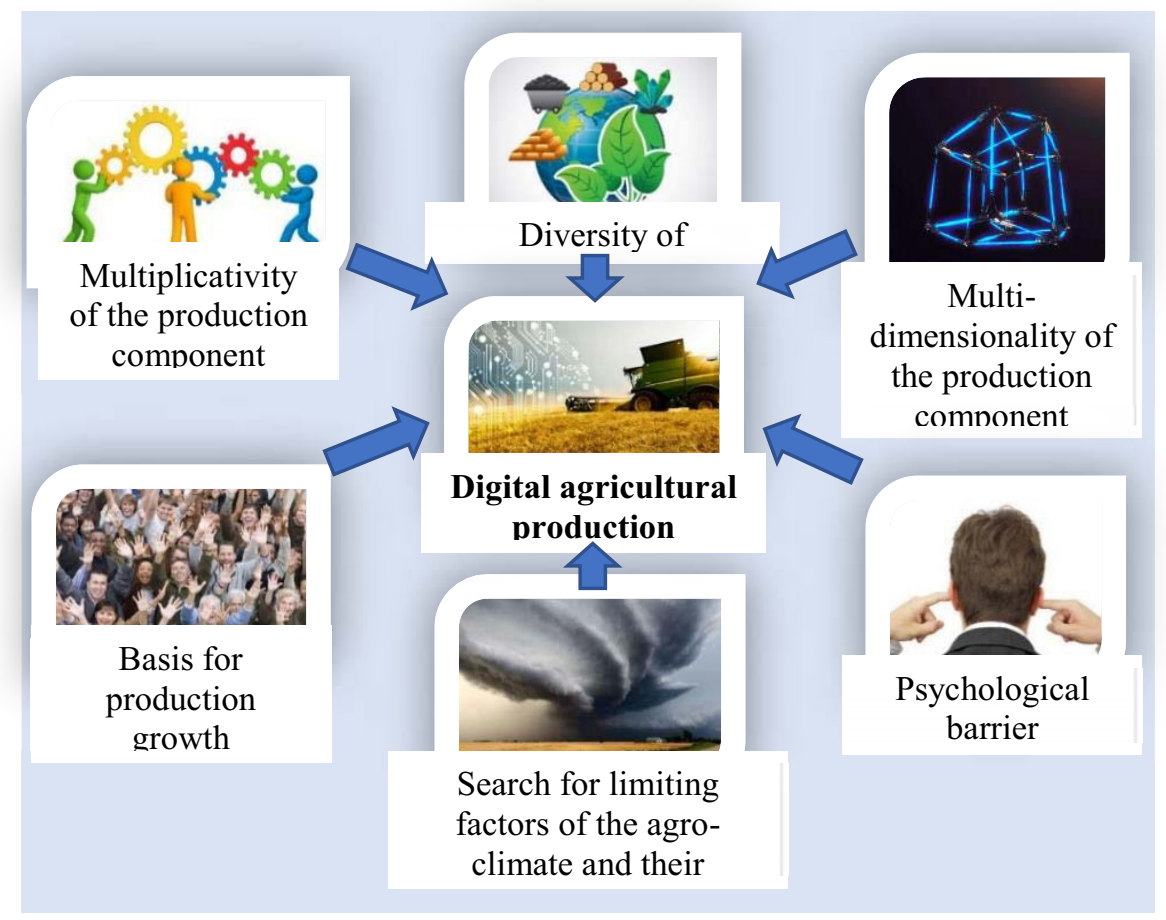

Fig.2. Problems of digitalization of agriculture. 
Among them are the following:

- multi-dimensionality of the production component (taking into account many factors that affect the production of agricultural products, and monitoring them);

- multiplicativity of objects (resources) of agricultural production;

- psychological barrier that prevents innovation (farmers are afraid of financial risk, especially small ones, etc.);

- availability of investments;

- the need to train personnel in new technologies (adoption of technologies, the impact of digitalization on a person's personality and work);

- availability of digital infrastructure (Internet, equipment, etc.).

At the moment, there are no means to get $100 \%$ reliable forecasts. However, foreign experience and the experience of some advanced farms in Russia shows that the installation of local weather stations allows you to get more accurate forecasts for rapid response to changes in weather conditions. In addition, the creation of a single portal for farmers will allow timely implementation of measures to protect crops. It should provide an opportunity to exchange information about the occurrence and spread of disease foci and the movement of pests.

In addition, there are psychological barriers, despite the visible advantages of innovative technologies. They are associated with the fact that farmers either do not accept the benefits of new technologies, or they need a long time to start the implementation process, as well as with the risks associated with investment [18].

The technological and digital delay between the Russian agricultural sector and foreign markets is still growing. About 112, 9 thousand IT specialists is in the agricultural sector in the Russian Federation, which is $2.4 \%$ of the employed population in the agro-industrial sector. At the same time, in the leading countries (USA, Germany, Great Britain) this indicator is $4.3,4.5,4$, and $1 \%$, respectively (figure 3). Thus, another 90 thousand IT specialists in agriculture are needed to achieve this indicator in Russia [14]. It is also necessary to review the training structure so that agricultural workers have the skills to work with sensors, drones, devices and software products.

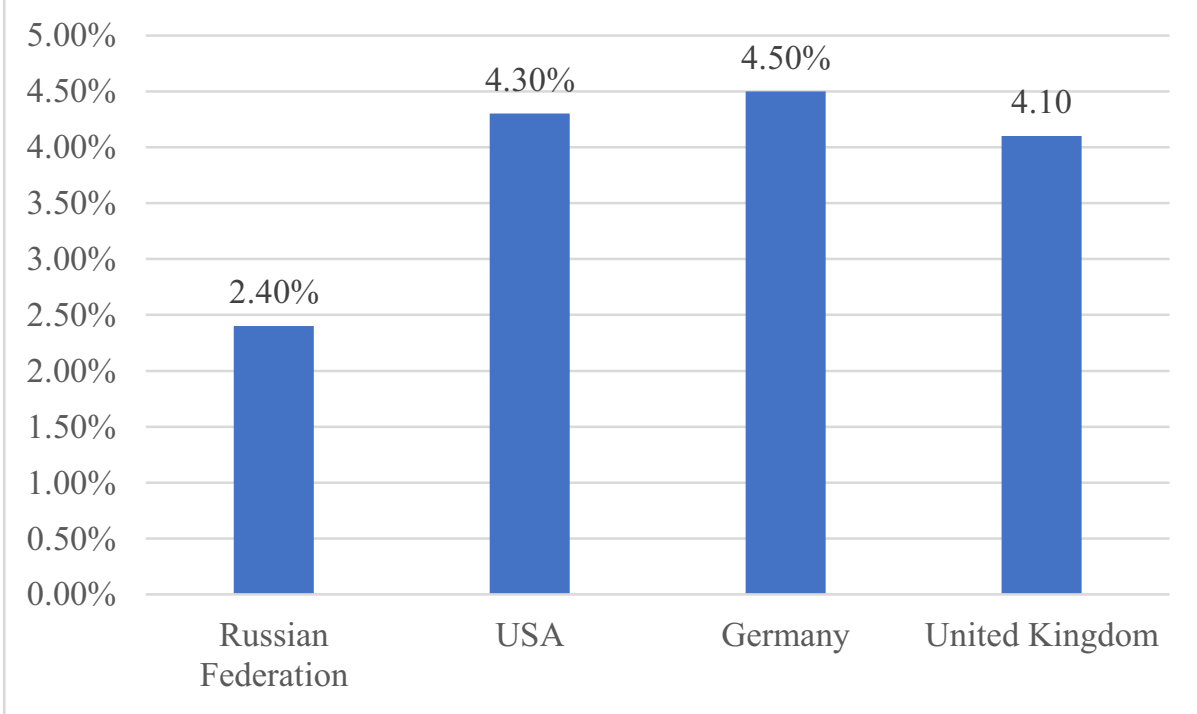

Fig.3. The share of IT specialists in agriculture from the total number of agribusiness employees (according to the Analytical center of the Ministry of agriculture of Russia). 
The information resources needed by agricultural producers are quite scattered and poorly systematized in Russia. The state of the information infrastructure and the promotion of information technologies among the rural population are significantly inferior to similar indicators in cities. Therefore, it is necessary to increase the area of Internet coverage in rural areas, thereby providing farmers with access to digitalization products; to provide farms with the necessary equipment (computers, servers, office equipment, etc.); it is necessary to create a unified database for agricultural producers [19].

The presence of a strategy for the implementation of digital technologies and digitalization tools will give an understanding and possible ways, when and how to implement the implementation. Then every farmer will understand the advantages and necessity of integration digital technologies in their farm [1].

\section{Conclusion}

The analysis of the mutual influence of agricultural production facilities allowed us to establish by analogy the types of resources that characterize and determine the development of production. The multiplicativity of the entire set of agricultural production resource is proved by the method of land-based transition is proved. The prospects of this direction of development based on the world experience of digitalization of agriculture are shown. Objective factors that hinder the widespread use of digital technologies as a tool to accelerate the development of agricultural production are identified.

\section{References}

1. T. Hovhannisyan, P. Efendyan, M. Vardanyan, Creation of a digital model offields with application of DJI phantom 3 droneand the opportunities of its utilization in agriculture. Annals of Agrarian Science, 16(2), 177-180 (2018) doi:10.1016/j.aasci.2018.03.006

2. D. C. Rose, R. Wheeler, M. Winter, M. Lobley, C.-A. Chivers, Agriculture 4.0: Making it work for people, production, and the planet, Land Use Policy, 100, 104933 (2021) doi: 10.1016/j.landusepol.2020.104933

3. R. Sharma, S. Parhi, A. Shishodia, Industry 4.0 Applications in Agriculture: CyberPhysical Agricultural Systems (CPASs), Advances in Mechanical Engineering, 807813; (2020) doi: 10.1007/978-981-15-3639-7_97

4. P. W. B. Phillips, J.-A. Relf-Eckstein, G. Jobe, B. Wixted, Configuring the new digital landscape in western Canadian agriculture, NJAS - Wageningen Journal of Life Sciences, 90, 100295 (2019) doi: 10.1016/j.njas.2019.04.001

5. T. Talaviya, D. Shah, N. Patel, H. Yagnik, M. Shah, Implementation of artificial intelligence in agriculture for optimisation of irrigation and application of pesticides and herbicides, Artificial Intelligence in Agriculture, 4, 58-73 (2020) doi: 10.1016/j.aiia.2020.04.002

6. K. Jha, A. Doshi, P. Patel, M. Shah, A comprehensive review on automation in agriculture using artificial intelligence, Artificial Intelligence in Agriculture, 2, 1-12 (2019) doi: 10.1016/j.aiia.2019.05.004

7. H. Panetto, M. Lezoche, J. E. H. Hormazabal, M. del Mar Eva Alemany Diaz, J. Kacprzyk, Special issue on Agri-Food 4.0 and digitalization in agriculture supply chains - New directions, challenges and applications, Computers in Industry, 116, 103188 (2020) doi: 10.1016/j.compind.2020.103188 
8. A. Sinha, G. Shrivastava, Pr. Kumar, Architecting user-centric internet of things for smart agriculture, Sustainable Computing: Informatics and Systems, 32, 88-102 (2019) doi: 10.1016/j.suscom.2019.07.001

9. F. Bertone, G. Caragnano, S. Ciccia1, O. Terzo1, E. Cremonese, Green Data Platform: An IoT and Cloud Infrastructure for Data Management and Analysis in Agriculture 4.0, Complex, Intelligent and Software Intensive Systems. Advances in Intelligent Systems and Computing, 365-374 (2021) doi:10.1007/978-3-030-50454-0_35

10. A. R.S.Marcala, M. Cunha, Development of an image-based system to assess agricultural fertilizer spreader pattern, Computers and Electronics in Agriculture, 162, 380-388 (2019) doi: 10.1016/j.compag.2019.04.031

11. K. Rijswijk, L. Klerkx, J. A. Turner, Digitalisation in the New Zealand Agricultural Knowledge and Innovation System: Initial understandings and emerging organisational responses to digital agriculture, NJAS - Wageningen Journal of Life Sciences, 90-91, 100313. (2019) doi:10.1016/j.njas.2019.100313

12. K. Rijswijk, L. Klerkx, J. A. Turner, Digitalisation in the New Zealand Agricultural Knowledge and Innovation System: Initial understandings and emerging organisational responses to digital agriculture, NJAS - Wageningen Journal of Life Sciences, 90-91, 100313 (2019) doi:10.1016/j.njas.2019.100313

13. Y. Chen, Y. Li, C. Li, Electronic agriculture, blockchain and digital agricultural democratization: Origin, theory and application, Journal of Cleaner Production, 268, 122071 (2020) doi: 10.1016/j.jclepro.2020.122071

14. E. V. Truflyak, N. Yu. Kurchenko, A. C. Kraymer, Monitoring and forecasting in the field of digital agriculture by the end of 2018, 100 (2019) (in Russian)

15. V. V. Alt, S. P. Isakova, E. A. Lapchenko, The mathematical model of forming of optimal combination of machineries and tractors park subject to social factor, 13th International conference on actual problems of electronic instrument engineering proceedings APEIE, 1(2), 523-526 (2016) doi: 10.1109/APEIE.2016.7806409

16. E. N. Bui, R. D. Searle, P. R. Wilson, et al., Soil surveyor knowledge in digital soil mapping and assessment in Australia, Geoderma Regional, 22, e00299 (2020) DOI: 10.1016/j.geodrs.2020.e00299

17. V. V. Alt, S. P. Isakova, E. A. Balushkina, Selection of technologies in crop production: approaches and methods used in information systems, Bulletin of Kazan state agrarian University, 1(57), 55-58, (2020) DOI: 10.12737/2073-0462-2020-52-58

18. A. Khondoker, Perception and adoption of a new agricultural technology: Evidence from a developing country, Technology in society, 55, 126-135 (2018) DOI: 10.1016/j.techsoc.2018.07.007

19. M. N. Dudin, K. P. Pavlova, E. E. Frolova etc., Information technologies as an incentive for Russian agriculture, Scientific papers series management, economic engineering in agriculture and rural development, 18, 143-152 (2018) 